\title{
THE INFLUENCE OF THE MICROGROOVES ON THE HYDRODYNAMIC PRESSURE DISTRIBUTION AND LOAD CARRYING CAPACITY OF THE CONICAL SLIDE BEARING
}

\author{
Adam Czaban \\ Gdynia Maritime University, Faculty of Marine Engineering \\ Morska Street 81-87, 81-225 Gdynia, Poland \\ tel.: +48586901304, fax: +48586901399 \\ e-mail: aczaban@am.gdynia.pl
}

\begin{abstract}
The aim of this work is to determine the hydrodynamic pressure distribution in oil film and the load carrying capacities of conical slide micro bearings with grooved sleeves. The results for some bearings examples are presented. For the bearings taken into account, the Reynolds equation was solved by the method of Finite Differences. In the calculations, the Reynolds boundary condition was applied. The simulation was performed for the conical slide micro bearings with the groves parallel to the cone generating line. The function of lubrication gap height for the conical slide bearings with sleeves covered with microgrooves was assumed on the basis of existing papers. The results obtained for the analogous bearings without the microgrooves are also shown, therefore the influence of microgrooves on the conical slide micro bearings can be observed. On the basis of the results, one can conclude, that applying microgrooves on the bearing sleeve surface causes the increase of the value of hydrodynamic pressure and longitudinal and transverse components of the load carrying capacity of the bearing. Furthermore, the effect of the microgrooves and their impact is noticeable in graphs of hydrodynamic pressure distribution. The applied method of investigation of the impact of microgrooves on a bearing operation is simpler and less expensive than the experimental studies, however it is necessary to verify that the results obtained with this method are correct and whether in fact applying microgrooves, besides form facilitate lubrication, causes the improvement in bearing operating parameters.
\end{abstract}

Keywords: conical slide bearing, pressure distribution, microgrooves, Reynolds equation, load carrying capacity

\section{Introduction}

The advantage of applying conical slide bearings, is that the friction pair constructed by one of such bearings can carry both transverse and longitudinal loads, so it may be less expensive than the use in this case, two bearings, i.e. one which carries the transverse forces, and second that carries the longitudinal forces. Due to the geometry of this kind of bearings, it is possible to manipulate the lubrication gap height, and as a result, also to change the values of longitudinal and transverse capacity forces. The conical slide bearings, however, are less frequent than journal slide bearings. Examples of the use of conical slide bearings is described e.g. in papers [1] and [2].

In the nowadays more common journal slide bearings, manufacturers use some methods of improving bearings operating properties, such as the use of porous surfaces of a bearing sleeve. Some manufacturers of bearings and micro bearings construct bearings sleeves covered with microgrooves. In papers $[3,4,5]$, the studies about surface topography of micro bearings with grooved sleeves, from computer HDDs and cooling fans, are described.

One can also find some slide bearing sleeves with microgrooves on their surface, which are used in industry, transportation and automotive [6].

Application of microgrooves on bearing sleeve surface causes lower wear of a slide bearing, due to the fact, that the microgrooves facilitate removal of contaminants from lubricating oil [7]. Furthermore, microgrooves help keeping oil in lubrication gap [6]. This is very significant in the boundary states of a bearing operation, i.e. when starting and stopping. 
The experimental study of the impact of microgrooves on a bearing operation could be difficult and expensive. Simpler and less expensive is to use simulation methods, which in spite of some simplifying assumptions, can give approximate data on the phenomena, that occur in the lubricating oil film of slide bearing with microgrooves on sleeve surface. The results of numerical calculations of hydrodynamic pressure distribution, load carrying capacity, friction forces and friction coefficient, for slide journal micro bearings with grooved sleeves, are presented in paper [8].

The aim of this work is to determine the hydrodynamic pressure distribution in oil films and also the load carrying capacities of slide conical micro bearings, which sleeve surface is covered with microgrooves. In order demonstrate the effect of microgrooves, there were also investigated hydrodynamic pressure distributions and load carrying capacities for corresponding conical slide bearings, but with smooth sleeves surfaces.

In some articles, certain information about different shapes of microgrooves, e.g. "herringbone microgrooves", which affect the stability of bearings [9] or "spiral grooves" [10] can be found. There are also some studies which show, that covering surfaces with microgrooves may reduce load carrying capacity of a bearing [11].

In this paper, there are presented results of hydrodynamic pressure distributions and load carrying capacities calculations, carried out for most simple conical slide bearing, i.e. at constant value of the lubrication gap height along the cone generating line. The microgrooves were placed parallel to the line that forms a cone and were uniformly distributed around the circumference of the sleeves.

The function of lubrication gap height $h(\varphi)$ for this case, was proposed in [12] and can be written in the following form:

$$
h_{C}(\varphi)=\varepsilon\left\{\frac{(1+\lambda \cos \varphi)}{\sin \gamma} \frac{2 \varepsilon_{g 1}}{\pi}\left[\frac{1}{2}+\frac{\pi}{4} \sin \left(\frac{2 \pi \varphi}{\varphi_{T}}\right)-\frac{1}{1 \cdot 3} \cos \left(\frac{4 \pi \varphi}{\varphi_{T}}\right)-\frac{1}{3 \cdot 5} \cos \left(\frac{8 \pi \varphi}{\varphi_{T}}\right)-\frac{1}{5 \cdot 7} \cos \left(\frac{12 \pi \varphi}{\varphi_{T}}\right)-\ldots \ldots .\right]\right\}
$$

for:

$\lambda-$ relative eccentricity,

$\varepsilon-$ radial clearance of conical micro bearing,

$\varepsilon_{g l}-$ dimensionless microgroove height,

$\varphi$ - circumferential coordinate,

$\varphi_{T}$ - parameter, which determines the distance between microgrooves,

$\gamma \quad-$ angle between conical surface and the cross section plane of the journal.

\section{The simulations and results}

The determination of hydrodynamic pressure distribution in a bearing lubrication gap was based on numerical solution of Reynolds equation. By using the conical coordinate system $\left(\varphi, y_{c}\right.$, $\mathrm{x}_{\mathrm{c}}$ ) described in [13], the Reynolds equation can be written in the following form [13]:

$$
\frac{1}{X_{c}} \frac{\partial}{\partial \varphi}\left[\frac{h_{C}^{3}}{\eta} \frac{\partial p}{\partial \varphi}\right]+\frac{\partial}{\partial x_{c}}\left[\frac{X_{c} h_{C}^{3}}{\eta} \frac{\partial p}{\partial x_{c}}\right]=6 \omega X_{c} \frac{\partial h_{C}}{\partial \varphi},
$$

for: $0 \leq \varphi<2 \pi \theta_{l}, 0 \leq \theta_{l}<1,0 \leq x_{c} \leq 2 b_{c}$, where:

$p=p\left(\varphi, x_{c}\right) \quad-$ hydrodynamic pressure,

$h=h\left(\varphi, x_{c}\right)-$ lubrication gap height,

$X_{c}=R+x_{c} \cos \gamma$,

$\gamma \quad-$ angle between conical surface and the cross section plane of the journal,

$R \quad$ - radius of a bearing shaft in the smallest cross section of a bearing,

$2 \cdot b_{c} \quad-$ length of the cone generating line,

$\eta \quad-$ dynamic viscosity of lubricating oil,

$\theta_{1} \quad-$ parameter, which describes the end of the oil film. 
In the calculations, the Reynolds boundary condition [14] was applied. The function of lubrication gap height for the conical slide bearings with microgrooves is described by equation (1), while the lubrication gap height of the conical slide bearings with smooth sleeves surfaces can be described with the same dependency for $\varepsilon_{g l}=0$, so that gives:

$$
h_{C}(\varphi)=\varepsilon \frac{(1+\lambda \cos \varphi)}{\sin \gamma} \text {. }
$$

In this work, there were performed the calculations for the conical slide bearings, for which $R=2 \cdot 10^{-3}[\mathrm{~m}], \varepsilon=10^{-6}[\mathrm{~m}]$, the rotational speed $\omega=7200 \mathrm{rpm}$ and for bearings with microgrooves $\varepsilon_{g l}=-0.04$ (which corresponds to $4 \%$ of a radial clearance). In each case, the 25 microgrooves spaced a constant distance apart, occurred on a surface covered by oil film.

In the calculations, with reference to [15], there was assumed a constant value of the dynamic viscosity, which is $\eta=18 \cdot 10^{-3}[\mathrm{~Pa} \cdot \mathrm{s}]$. Moreover, the assumed model implies that the lubrication is isothermal, the flow of oil is laminar and independent of time, and the bearing is smooth with the angular length of sleeve of $360^{\circ}$.

The simulations were performed with the method of Finite Differences. The Mathcad 14 software was used and the procedures described in book [16].

The results were presented in the form of graphs. The hydrodynamic pressure distribution for each case was shown in two different perspectives. In graphs, there were detailed such values, as: the dimensionless bearing length $L_{l}=b_{c} / R$, the relative eccentricity $\lambda$, the values of the angle, where oil film ends $\varphi_{k}$, the angles $\gamma$ between conical surface and the cross section plane of the journal, the calculated values of maximum hydrodynamic pressure in oil film $p_{\max }$ and of the longitudinal $C_{w}$ and transverse $C_{p}$ load carrying capacities.

Figure 1 shows results for bearing with the dimensionless length of $L_{1}=0.5, \gamma=80^{\circ}$ and $\lambda=0.4$.

Figure la corresponds to conical slide bearing with sleeve surface with microgrooves, while Fig. $1 \mathrm{~b}$ is for the similar bearing, however with the smooth sleeve surface.
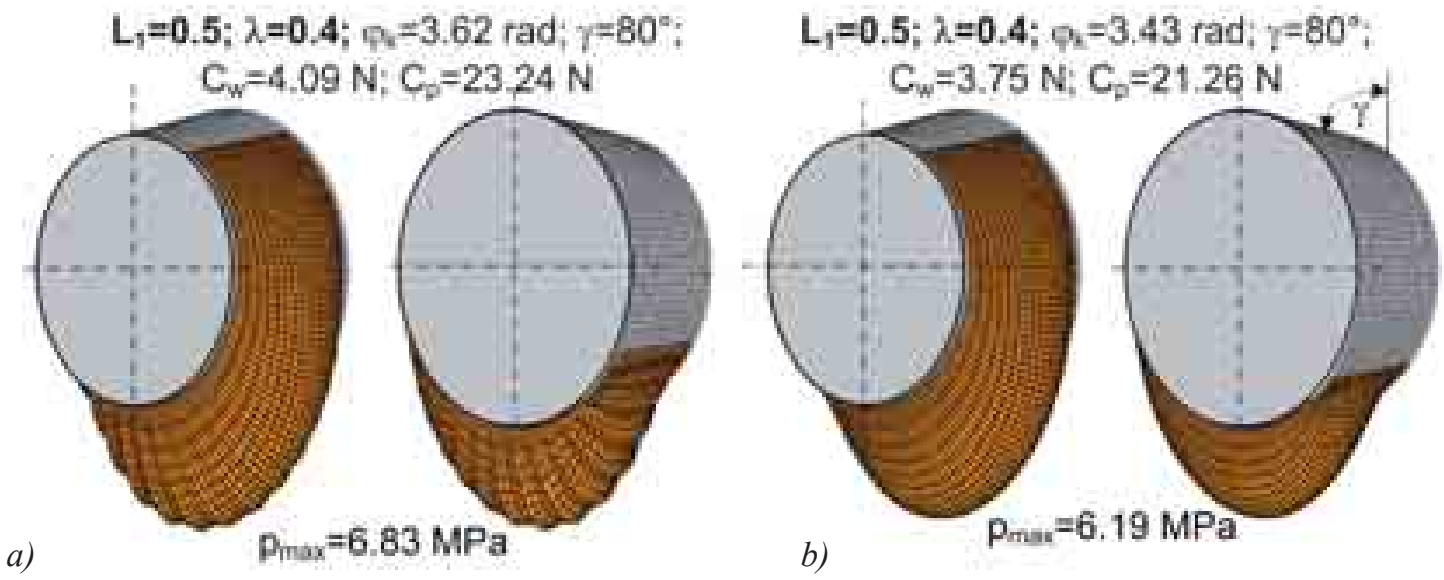

Fig. 1. The pressure distribution in conical slide bearing (dimensionless bearing length - 0.5, eccentricity ratio - 0.4, characteristic angle $\left.-80^{\circ}\right)$ : a) bearing with grooved sleeve surface, b) bearing without grooves

In Fig. 1a, for the bearing with microgrooves, besides the changes of the hydrodynamic pressure as for the bearing with conventional surfaces, the changes of hydrodynamic pressure resulting from the occurrence of microgrooves can be observed. Along the circumferential coordinate, at the microgrooves locations, the pressure values increases. The calculated values of $p_{\max }, C_{w}$ and $C_{p}$ are grater then for the analogous conventional bearing, shown in Fig. 1b.

In a similar manner, the results were presented in Fig. 2 and Fig. 3. Fig. 2a shows the hydrodynamic pressure distribution in the oil film for the bearing with grooved sleeve surface, with dimensionless length of $L_{1}=0.5, \gamma=80^{\circ}$ and relative eccentricity of $\lambda=0.5$. In Fig. $2 \mathrm{~b}$, there 
is analogous bearing, i.e. with the dimensionless length of $L_{1}=0.5, \gamma=80^{\circ}, \lambda=0.5$, but with smooth surface of the sleeve. In Fig. 3a and Fig. $3 b$ are shown results for bearing with the same dimensionless length of $L_{1}=0.5$, angle of $\gamma=80^{\circ}$, while relative eccentricity is $\lambda=0.6$. Fig. $3 \mathrm{a}$ shows results for conical slide bearing with grooved surface of the sleeve, when Fig. $3 \mathrm{~b}$ shows the hydrodynamic pressure distribution in the oil film of bearing with smooth surface of the sleeve.

Figure 1, 2 and 3 thus present comparison for similar conical slide bearings, where only the value of relative eccentricity changes from 0.4 to 0.6 . In each example, according to resulted data, the application of microgrooves on the sleeves of conical slide bearings increases the values of the hydrodynamic pressure and of longitudinal and transverse load carrying capacities of such bearing.

a)

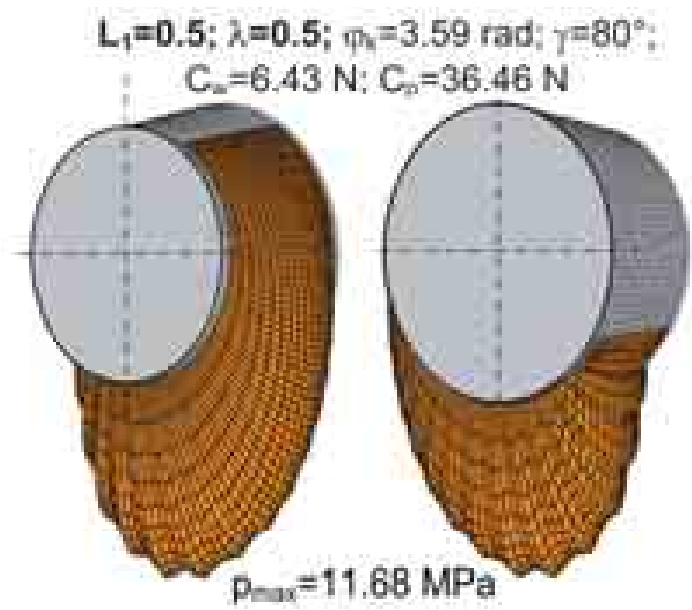

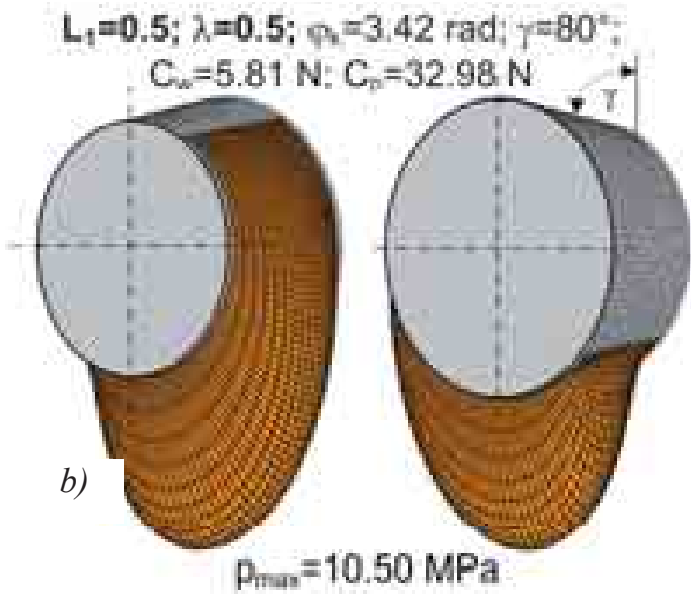

Fig. 2. The pressure distribution in conical slide bearing (dimensionless bearing length - 0.5, eccentricity ratio - 0.5, characteristic angle $\left.-80^{\circ}\right)$ : a) bearing with grooved sleeve surface, b) bearing without grooves
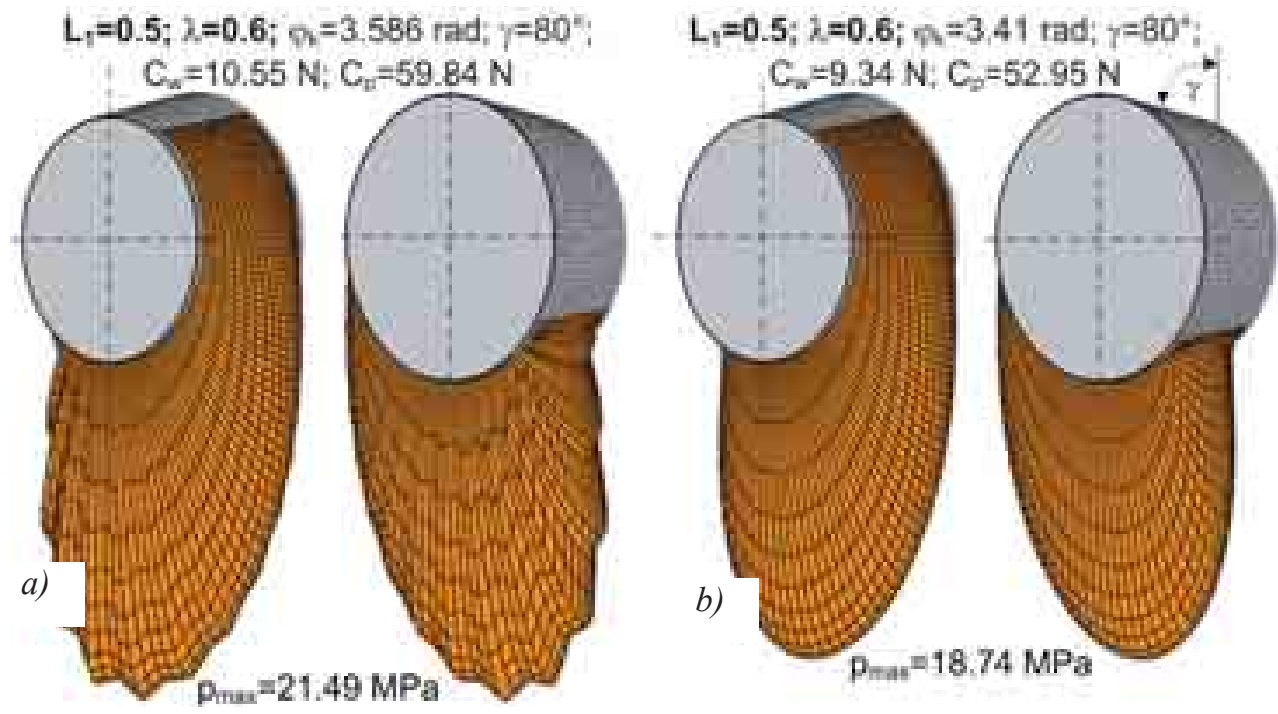

Fig. 3. The pressure distribution in conical slide bearing (dimensionless bearing length - 0.5, eccentricity ratio - 0.6, characteristic angle $\left.-80^{\circ}\right)$ : a) bearing with grooved sleeve surface, b) bearing without grooves

Figure 4, 5 and 6 show numerical results of the hydrodynamic pressure distribution calculation and also obtained values of $p_{\max }, C_{w}$ and $C_{p}$ for the conical slide bearings with the dimensionless length of $L_{1}=1.5$ and angle $\gamma=60^{\circ}$. Fig. 4 concerns the bearing with the relative eccentricity of $\lambda=0.4$, Fig. 5 corresponds to $\lambda=0.5$, while Fig. 6 to $\lambda=0.6$. In Figs. 4a, 5a, 6a results for the bearings with grooved surfaces of the sleeves are presented, which can be compared with related the Figs., respectively: 4b, 5b, 6b, which correspond to the conventional bearings with smooth surfaces of the sleeves. These examples of simulations also demonstrate, 
that covering the surface of the bearing sleeve with microgrooves causes the increase of the hydrodynamic pressure values in the lubricating oil film and due to this, the load carrying capacities of the bearing are greater.

The percentage increases of $p_{\max }, C_{w}$ and $C_{p}$ for the considered conical slide bearings with grooved surfaces of the bearings sleeves, compared to the analogous bearings with smooth surfaces, are presented in Tab. 1.
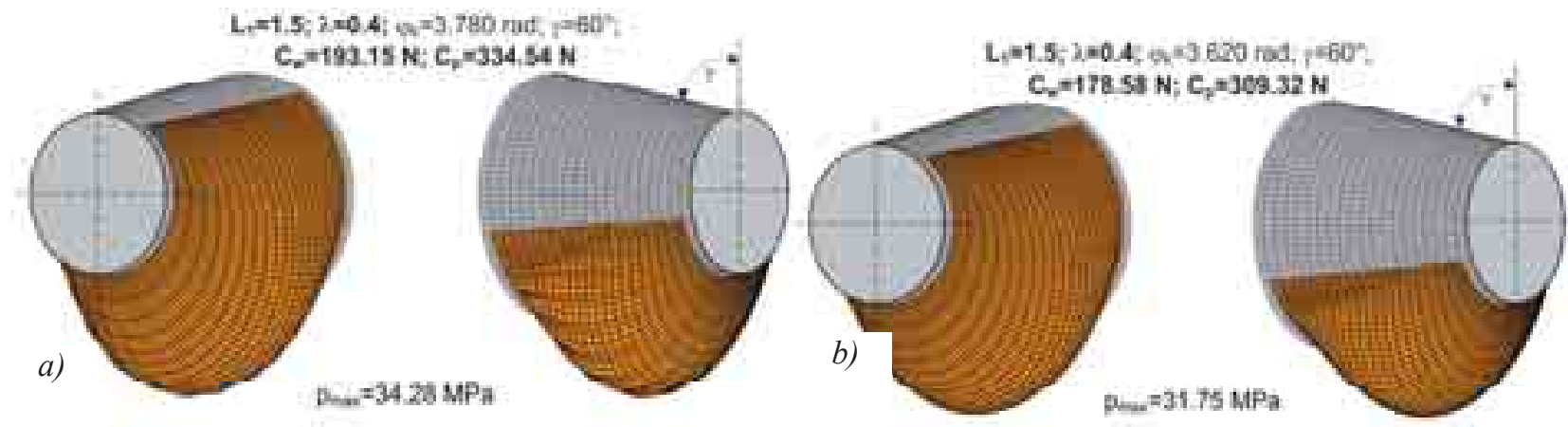

Fig. 4. The pressure distribution in conical slide bearing (dimensionless bearing length - 1.5, eccentricity ratio - 0.4, characteristic angle $\left.-60^{\circ}\right)$ : a) bearing with grooved sleeve surface, b) bearing without grooves
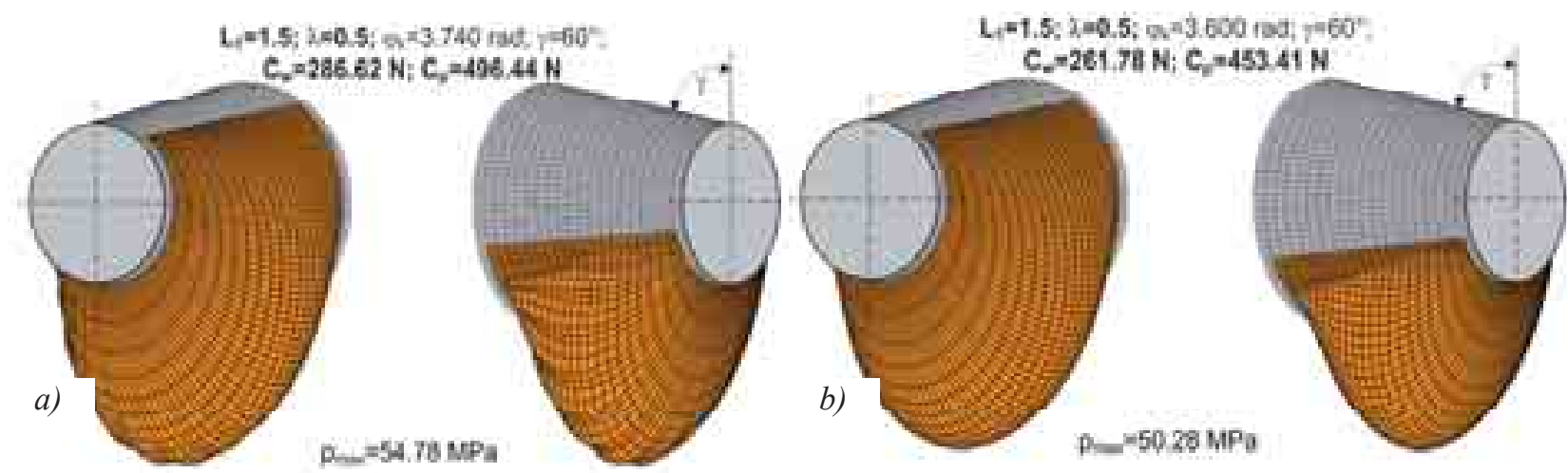

Fig. 5. The pressure distribution in conical slide bearing (dimensionless bearing length - 1.5, eccentricity ratio - 0.5, characteristic angle $\left.-60^{\circ}\right)$ : a) bearing with grooved sleeve surface, b) bearing without grooves
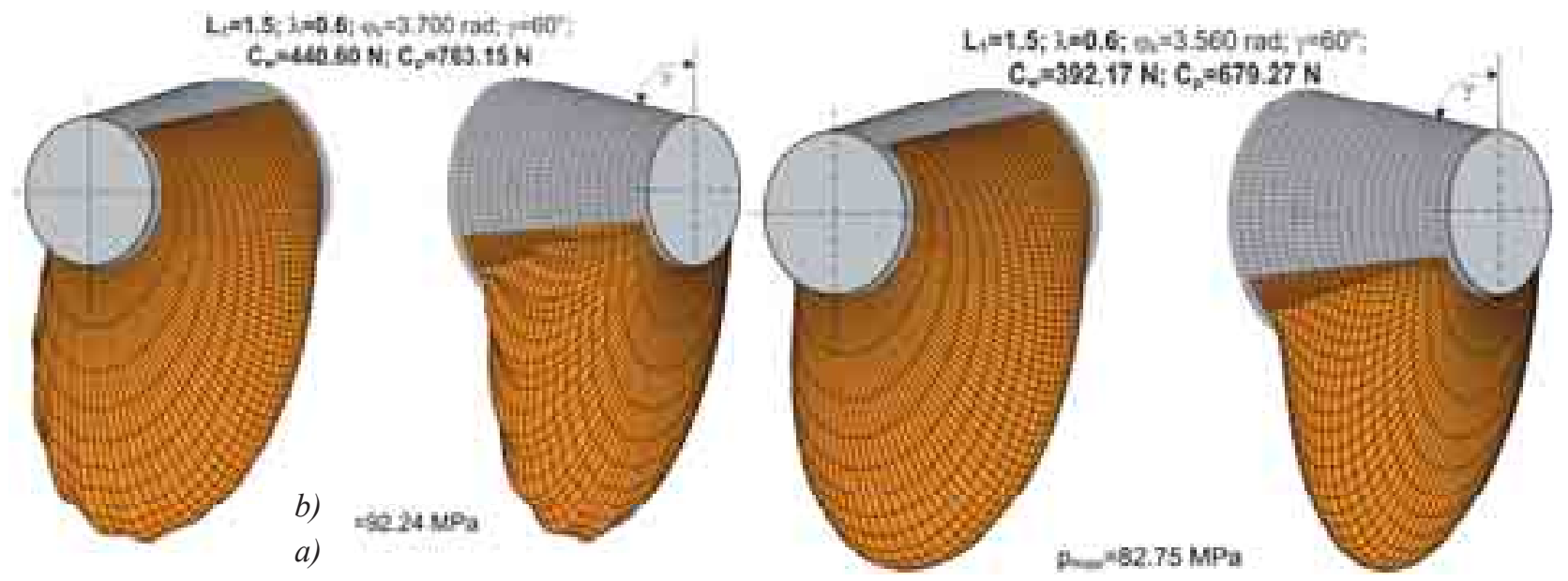

Fig. 6. The pressure distribution in conical slide bearing (dimensionless bearing length - 1.5, eccentricity ratio - 0.6, characteristic angle $\left.-60^{\circ}\right)$ : a) bearing with grooved sleeve surface, b) bearing without grooves 
Tab. 1. The percentage increases of $p_{\max }, C_{w}, C_{p}$ for the considered bearings with microgrooves

\begin{tabular}{|c|c|c|c|c|c|c|}
\hline & \multicolumn{6}{|c|}{ The percentage increases of $\mathrm{p}_{\max }, \mathrm{C}_{\mathrm{w}}, \mathrm{C}_{\mathrm{p}}$} \\
\hline & \multicolumn{3}{|c|}{$L_{1}=0.5 ; \gamma=80^{\circ}$} & \multicolumn{3}{|c|}{$L_{1}=1.5 ; \gamma=60^{0}$} \\
\hline & $\lambda=0.4$ & $\lambda=0.5$ & $\lambda=0.6$ & $\lambda=0.4$ & $\lambda=0.5$ & $\lambda=0.6$ \\
\hline$p_{\max }$ & $10.3 \%$ & $11.2 \%$ & $14.7 \%$ & $8.0 \%$ & $8.9 \%$ & $11.5 \%$ \\
\hline$C_{w}$ & $9.1 \%$ & $10.7 \%$ & $13.0 \%$ & $8.2 \%$ & $9.5 \%$ & $12.3 \%$ \\
\hline$C_{p}$ & $9.3 \%$ & $10.6 \%$ & $13.0 \%$ & $8.2 \%$ & $9.5 \%$ & $12.3 \%$ \\
\hline
\end{tabular}

\section{Observations and conclusions}

This research concerns the hydrodynamic lubrication of conical slide bearings with sleeves covered with microgrooves. To investigate the influence of microgrooves on the hydrodynamic pressure and load carrying capacities of a bearing, the numerical simulations were performed. The results for bearings with microgrooves were compared with the results obtained for analogous conical slide bearings with smooth surfaces of the sleeves. The theoretical model of the lubrication gap height for conical slide bearings with microgrooves was assumed in the form presented by equation (1).

On the basis of the presented results for conical slide bearings, it can be concluded, that microgrooves on the surfaces of slide bearings sleeves cause the increase of the values of hydrodynamic pressure and longitudinal and transverse components of load carrying capacity of such bearings. It should be noted, that in this paper, the results of calculations for some examples of micro bearings were presented, that is bearings, for which the value of radial clearance is very low and applying the microgrooves on the bearing sleeve surfaces causes relatively large changes in the value of lubrication gap height.

Many factors affect the convergence of the obtained values. The adopted method of investigation of the effect of microgrooves is approximate and some simplifying assumptions are imposed. Furthermore, the used software and computer have limited memory and computing speed, therefore increasing the number of grid nodes where the values of hydrodynamic pressure are calculated is also bounded. The assumed function of lubrication gap height for conical slide bearings with microgrooves is a mathematical model that does not reflect the real shape of the microgrooves.

The presented results concern only simulations for the longitudinal microgrooves with one value of depth. As a result of applying microgrooves, there were occurred significant changes in the values of hydrodynamic pressure and load carrying capacities. The studies do not allow for a clear answer, whether the microgrooves cause such a significant improvement of the conical slide bearings properties. The results obtained by this method should be verified, for example, by comparing with data obtained by the method of Finite Volumes. It is also planned to perform simulations for bearings and micro bearings with the sleeve surfaces covered with microgrooves of different shapes, depths and distances between them.

\section{References}

[1] Information on http://www.sumobrain.com/patents/wipo/Slide-bearing-crank-shafts-internal/ WO1992018782.html.

[2] Information on http://www.spandaupumpen.de/en/applications/optical-machines/fabricationmethods.html. 
[3] Czaban, A., Miszczak, A., Surface topography of non-operated slide journal micro-bearings, Journal of KONES. Powertrain and Transport, Vol. 18, No. 2, pp. 109-115, Warsaw 2011

[4] Miszczak, A., Czaban, A., Labuda, W., Surface topography of operated slide journal microbearings used in computer fan, KONES 2012 (in-press).

[5] Miszczak, A., W., Surface topography of operated slide journal micro-bearings used in $H D D$, KONES 2012 (in-press).

[6] Information on http://www.enex.net.pl/?a=po\&i=14.

[7] Sęp, J., Kucaba-Piętal, A., Experimental testing of journal bearings with two-component surface layer in the presence of an oil abrasive contaminant, Wear 249, pp. 1090-1095, 2001.

[8] Miszczak, A., Operating parameters of slide micro-bearings with consideration of oil temperature changes and micro-grooves on sleeve surface, KONES 2012 (in-press).

[9] Jang, G. H., Yoon, J. W., Stability analysis of a hydrodynamic journal bearing with rotating herringbone grooves, Journal of Tribology, Vol. 125, pp. 291-300, 2003.

[10] Sęp, J., The flow oil analysis in the gap of a journal bearing with a circumferential groove, Tribology. Scientific Problems of Machines Operation and Maintenance, Vol. 44, No. 2, pp. 19-33, 2009.

[11] Cupillard, S., Cervantes, M., Glavatskih, S., Thermohydrodynamic analysis of a journal bearing with a microgroove on the shaft, International Symposium on Transport Phenomena, No. 22, Delft, 2011.

[12] Wierzcholski, K., Kształty nanorowków i żeberek na powierzchniach mikrołożysk, Tribologia. Teoria i Praktyka, Nr 5/2009, pp. 211-220, 2009.

[13] Wierzcholski, K., Miszczak, A., Capacity enhancement in HDD conical micro-bearings, Tribologia. Teoria i praktyka, Nr 4/2009, pp. 251-258, 2009.

[14] Hori, Y., Hydrodynamic lubrication, Springer-Verlag, Tokyo 2006.

[15] Asada, T., Saito, H., Asaida, Y., Itoh, K., Design of hydrodynamic bearings for high-speed $H D D$, Microsystem Technologies 8, pp. 220-226, 2002.

[16] Miszczak, A., Analiza hydrodynamicznego smarowania ferrociecza poprzecznych łożysk ślizgowych, Fundacja Rozwoju Akademii Morskiej, Gdynia 2006. 